\title{
Ulcerative Colitis: Shifting Sands
}

\author{
Geert R. A. M. D'Haens ${ }^{1}\left[\right.$ ] James O. Lindsay ${ }^{2,3}\left[\right.$ ] $\cdot$ Remo Panaccione ${ }^{4}\left(\mathbb{D} \cdot\right.$ Stefan Schreiber $^{5}$
}

Published online: 2 March 2019

(c) The Author(s) 2019

\begin{abstract}
Ulcerative colitis (UC) is a chronic inflammatory bowel disease associated with considerable disease burden. We review some current misconceptions about UC in adults with the aim of optimizing care for patients. Although UC and Crohn's disease (CD) are considered discrete diseases, distinctions between them are not always clear-cut and phenotypes may change over time. Patient management should take into account disease manifestations, disease severity and extent, and response to prior treatments. Although disease extent often defines severity, distal UC is not always less disabling than extensive disease as patients can progress to more extensive disease. In addition, severe proctitis can give rise to severe and debilitating symptoms, with a substantial impact on health-related quality of life. UC carries an increased risk of colorectal cancer (CRC) compared with CD; however, more recent data indicate a similar risk of CRC in CD with colonic involvement as with UC. Corticosteroids are widely used to induce remission in UC, and prolonged use of steroids in patients with UC is common, but corticosteroid-free maintenance of remission is an important therapeutic goal. Although biologic therapies provide a valuable treatment option in UC, they are not clinically effective in all patients and are also associated with secondary loss of response.
\end{abstract}

\section{Key Points}

Clarification of common misunderstandings regarding ulcerative colitis (UC) could help to optimize patient care.

Importantly, UC should not be regarded as completely different to Crohn's disease as classification may be oversimplified, the disease genotypes often overlap, and both can be associated with an increased risk of developing colorectal cancer.

With regard to the treatment of UC, corticosteroids are not appropriate for maintenance therapy due to adverse effects and the importance of corticosteroid-free remission as a key target. In addition, healthcare providers should also be aware that biologics often fail to induce remission, and secondary non-responsiveness can develop.

Geert R. A. M. D’Haens

g.dhaens@amc.uva.nl

1 Department of Gastroenterology, Academic Medical Center, Meibergdreef 9, 1100 DZ Amsterdam, The Netherlands

2 Department of Gastroenterology, The Royal London Hospital, Barts Health NHS Trust, London E1 1BB, UK

3 Centre for Immunology, Blizard Institute, Queen Mary University of London, London E1 2AT, UK

\section{Introduction}

Ulcerative colitis (UC) is a chronic inflammatory bowel disease (IBD) limited to the colonic mucosa and submucosa, involving part or all of the colon, and characteristically resulting in symptoms such as urgency of defecation, tenesmus, bloody diarrhea, abdominal pain, and fatigue [1, 2]. Although the pathogenesis of UC is not completely understood, it is thought to result from an inappropriate immune response to gastrointestinal (GI) antigens and/or environmental triggers in genetically susceptible individuals [3-5]. UC has a negative impact on patients' health-related quality of life (HRQoL) [6, 7]. Despite the considerable disease burden and progressive nature of this condition, healthcare providers responsible for the care of patients with UC often underestimate or misinterpret the impact of the disease [8].

The global prevalence of UC has been reported to range from 2.42 to $298.5 / 100,000$, with the highest incidence reported in North America and Northern Europe [9]. UC is

4 Inflammatory Bowel Disease Clinic, University of Calgary, Calgary, AB T6G 2X8, Canada

5 Klinik für Innere Medizin I, Universitätsklinikum Schleswig-Holstein, Campus Kiel, 24105 Kiel, Germany 
currently more prevalent in developed than developing countries, but the incidence is increasing globally, particularly in regions that previously had low incidence rates, including Asia and South America [9, 10]. Therefore, it is important to have a global understanding of the reality and myths that surround the appropriate management of UC.

This article seeks to highlight some common misunderstandings with regard to UC and the management of adult patients with UC, and to provide suggestions to optimize care for patients with this disease.

\section{Current Misunderstandings}

\subsection{Crohn's Disease (CD) and Ulcerative Colitis (UC) are Completely Different Diseases}

UC and Crohn's disease (CD), the most common forms of IBD, are generally considered to be discrete diseases [3]. Classification of IBD has been reported to be critical to ensure optimized clinical management [11]. Accurate classification has potential benefits in order to define disease prognosis, give appropriate patient counseling, and decide on the most appropriate form of therapy [12]. For example, surgical options differ between UC and CD, with total colectomy and ileal pouch-anal anastomosis (IPAA) considered an appropriate option in cases of medically refractory UC, but generally unsuitable for patients with CD [13]. However, the current classification into $\mathrm{UC}$ and $\mathrm{CD}$ is oversimplified and may not be appropriate.

Classification of UC and CD is generally based on endoscopic appearance, location and distribution of lesions, and histopathology. Inflammation in UC is limited to the colon and is usually continuous, whereas $\mathrm{CD}$ involves any part of the GI tract, presents with non-continuous lesions, and complications such as strictures, abscesses, and fistulas can occur [14]. Histologically, inflammatory changes in UC are limited to the mucosa and submucosa with cryptitis and crypt abscesses, whereas in CD there is transmural inflammation and submucosal thickening, with ulceration and granuloma formation in some patients [15].

Despite these differences, distinguishing UC and CD can be challenging, and it has been suggested that combinations of inflammatory, genetic and serologic markers [16] with colonoscopy [17] are used. Various imaging techniques are available, in addition to colonoscopy, in the diagnosis and management of IBD, including abdominal ultrasound and magnetic resonance enterography [18]. Endoscopic ultrasound has also been proposed as a tool to differentiate these diseases [17].

Exceptions to classification criteria based on disease location are sometimes observed, such as discontinuous lesions [19] (including cecal patch [20] and rectal sparing [19, 21]) in UC. Rectal sparing and backwash ileitis are commonly seen in patients with primary sclerosing cholangitis and IBD [22]. Histologic features typical of UC may occur in resections from patients with $\mathrm{CD}$, and vice versa [11]. Additionally, while perinuclear antineutrophil cytoplasmic antibodies (p-ANCA) are considered a recognized marker for UC, this marker has limited value for individual diagnosis; $20 \%$ of patients with $\mathrm{CD}$ in one study [23], and $24 \%$ in another [24], expressed p-ANCA. Crohn's colitis that is p-ANCApositive may look very much like UC in the left colon but has a more typical appearance of $\mathrm{CD}$ in the right colon [25]. A small proportion of patients undergoing a proctocolectomy and IPAA for UC may subsequently develop CD [26, 27]; whether this is due to post-surgical development of $\mathrm{CD}$, misdiagnosis of the original disease, or a true overlap between UC and CD is uncertain. Furthermore, in a recently published pilot study investigating zonulin (a biomarker of intestinal permeability), although significant differences in serum zonulin concentration were observed for patients with IBD compared with healthy controls, no differences were observed between patients with CD and UC [28].

Studies focused on the genotypes of patients with IBD have raised questions on the 'classic' classification into UC and $\mathrm{CD}$; gene expression in colon mucosal pinch biopsies from patients with UC and CD is very similar [29], DNA from peripheral whole-blood samples of patients with UC and $\mathrm{CD}$ shares genetic variants related to impaired adaptive immune response [30], and genome-wide association studies have identified extensive overlap in the genetic susceptibility architecture between UC and CD [31]. A recent large genotype association study reported in The Lancet suggested that disease location — an intrinsic aspect of IBD—is at least partially genetically determined, and concluded that IBD is better considered as a continuum of disorders comprising three groups (ileal $\mathrm{CD}$, colonic $\mathrm{CD}$, and $\mathrm{UC}$ ), rather than as either UC or CD [32]. In truth, more subtypes may belong to this spectrum, and clinical phenotyping may be too blunt to fully reflect the impact of underlying genetic causations. There is a need for more research in this area to define the most homogeneous patient populations possible as this is paramount for the performance of randomized controlled trials (RCTs) and clinical care.

In summary, considering $\mathrm{UC}$ and $\mathrm{CD}$ to be completely different diseases is an oversimplification; there are exceptions to classification criteria based on the location and distribution of lesions and histopathology, and overlaps in the genetic variants are seen in the two diseases.

\subsection{Distal Colitis is a Milder Form of UC}

UC is generally classified based on the extent and severity of disease [33], using the Montreal classification system, with extent categorized as ulcerative proctitis, left-sided/distal 
UC, or extensive UC/pancolitis, and severity categorized as clinical remission, mild, moderate, or severe. Severity of disease is defined as follows: (i) mild UC: four or fewer stools/day (with or without blood), absence of systemic symptoms, and normal inflammatory markers; (ii) moderate UC: four stools/day and minimum signs of systemic symptoms; and (iii) severe UC: six or more bloods/day, pulse rate of $\geq 90$ beats $/ \mathrm{min}$, temperature $\geq 37.5^{\circ} \mathrm{C}$, hemoglobin concentration $<105 \mathrm{~g} / \mathrm{L}$, and erythrocyte sedimentation rate $\geq 30 \mathrm{~mm} / \mathrm{h}$ [2, 34]. Indeed, US, European, and UK clinical guidelines recommend treatment approaches based on the classification of UC by extent and severity [35-38].

However, consideration of other issues such as response to prior medication when choosing between treatment options is recommended in European UC guidelines [35], and it has been suggested that treatment refractoriness, in addition to the severity and location of UC, should also drive treatment decisions [2]. In developing a UC clinical decision support tool, one group of gastroenterologists recommended risk stratification, such as disease risk, taking into account factors beyond the extent and severity of disease [39].

In clinical trials involving patients with UC, approximately $60 \%$ of the patient population have refractory leftsided/distal UC [40-42]. However, approximately $20 \%$ of patients initially diagnosed with distal UC will develop more extensive disease over time [43-45], and this figure has been reported to exceed $50 \%$ over 25 years [46]. It has been reported that progression of colitis is associated with a significantly higher rate of extraintestinal manifestations and corticosteroid refractoriness than distal colitis [47]. There is some evidence that extension of initially distal disease carries an increased risk of colectomy in comparison with extensive UC at diagnosis [45], although this was not the finding in a recently reported study [44]. The fact that the extent of disease might change, and that initially limited disease might have a worse clinical outcome than extensive disease, calls into question the usefulness of the extent of disease to classify UC.

It is commonly assumed that distal UC is less severe than extensive colitis, and therefore might not warrant use of some treatments. This idea is complicated by the fact that patients with limited proctitis are often excluded from RCTs. However, at a symptomatic level, patients with distal UC may have equally or even more burdensome symptoms, and lower HRQoL, than patients with extensive disease as it is accepted that the most troublesome symptoms of urgency, tenesmus, and incontinence are related to rectal inflammation [48]. In addition to urgency and tenesmus, a proportion of patients with proctitis or leftsided colitis suffer from paradoxical constipation, while abdominal pain and bloody diarrhea are more prominent in pancolitis [14, 48].
In summary, distal colitis should not be assumed to be milder than extensive colitis as symptoms associated with distal disease may be more burdensome than those associated with extensive disease, and progression of initially distal disease has been reported to result in poor patient outcomes.

\subsection{Malignancy is More of a Problem in UC than in CD}

There is a recognized increased risk of colorectal cancer (CRC) in patients with IBD, with a reported annual increase of $0.5-1.0 \%, 8-10$ years after diagnosis [49]. For both CD and UC, the risk of developing CRC increases with the duration and extent of disease, younger age at diagnosis, familial association, and primary sclerosing cholangitis [49]. The CRC risk in UC has been studied extensively and, in a metaanalysis, the overall prevalence has been estimated to be $3.7 \%$, with a cumulative risk of $2 \%$ after 10 years, $8 \%$ after 20 years, and $18 \%$ after 30 years, reported in 2004 [50]. The use of surveillance colonoscopy for earlier detection of CRC is recommended for patients with left-sided and extensive UC [51]. However, the incidence of CRC in patients with $\mathrm{UC}$ has been reported to have decreased over time between 1971 and 2000 [52], and a meta-analysis including studies up to the end of 2013 also reported a decreasing risk over the previous six decades [53]. A more recent study reports the cumulative risk to be $1.4 \%, 2.0 \%$, and $3.0 \%$ after 10,20 , and 30 years, respectively [54]. Improved colectomy policies and effective surveillance programs might have contributed to a decline in CRC risk in UC [55], as might the use of therapies that allow better control of inflammation, such as biologics $[53,56]$. However, it is also likely that the magnitude of risk for $\mathrm{CRC}$ in UC has been overestimated in the past due to the use of aging cohorts and referral populations, in contrast to more recent population-based studies. Historic studies have reported a lower risk of CRC in CD than UC [57, 58]; however, recent data suggest that Crohn's colitis carries a similar risk of CRC to UC $[59,60]$.

Colonoscopic surveillance programs for CRC in patients with UC were introduced more than 30 years ago [52], and surveillance of patients with IBD to detect dysplasia that might advance to $\mathrm{CRC}$ is recommended in relevant guidelines [61, 62]. Techniques used have evolved considerably over the last 30 years, with full-spectrum endoscopy [63] and chromoendoscopy [64] increasing the detection of dysplastic lesions. Recent surveillance guidelines recommend similar surveillance strategies for patients with UC and Crohn's colitis [61, 62], reflecting the evolving view of the relative risk of CRC in different types of IBD.

In summary, recent analyses suggest that there is a similar risk of CRC in Crohn's colitis and UC. 


\subsection{Corticosteroid Maintenance Treatment in UC is Acceptable}

Therapeutic options for the long-term maintenance of remission in UC are currently somewhat limited. Aminosalicylates are effective treatments for UC [35], but no clinically relevant effects have been demonstrated in CD [65]. Although corticosteroids remain the first-line induction treatment of choice in moderate to severe UC, corticosteroid-free remission is an established therapeutic target, and short- and longterm adverse effects should preclude their use as maintenance treatment [66]. Thiopurines have been shown to be effective in achieving and maintaining corticosteroid-free remission in UC [67-69]. Corticosteroid-induced toxicities include moon face, cutaneous effects, adrenal suppression, hypertension, glucose intolerance, infectious complications, osteonecrosis, osteoporosis, psychiatric effects, and cataracts [70]. Reports of patients who are receiving oral corticosteroids being at high risk of colectomy if they experience a moderate flare [71] also argue against the use of corticosteroids as maintenance treatment in UC.

Despite the contraindications for prolonged corticosteroid use, an analysis of US claims data reported that 10-24\% of patients with UC had, depending on index treatment, received corticosteroid treatment for more than 3 months of the 12-month study period [72]. Analysis of medical records in Olmsted County, MN, USA, also showed long-term corticosteroid use in patients with UC, with $12 \%$ of patients treated with corticosteroids for at least 6 months [73]. A recently published audit of British IBD clinics reported that approximately $15 \%$ of patients with IBD had received corticosteroids in excess of guidelines or had corticosteroid dependency, with excess exposure/dependency more common in moderate/severe UC than CD [74]. Use of tumor necrosis factor (TNF) antagonists and the existence of multidisciplinary IBD teams were both associated with lower levels of inappropriate long-term use of corticosteroids [75]. Finally, a recent large-scale survey of US gastroenterologists reported corticosteroid refractoriness and dependency as the most common drivers for initiating biologic therapies, with approximately $66 \%$ of respondents indicating this as a reason for prescribing a biologic [75].

It is critical that corticosteroids are not considered acceptable for the maintenance of remission in patients with UC. Well-documented corticosteroid-related toxicities, increased need for surgery due to disease flare while receiving corticosteroids, and the availability of agents with more favorable benefit:risk profiles all argue for the need to strive for corticosteroid-free remission in all patients.

In summary, the adverse effects of long-term use of corticosteroids should preclude their use for maintenance of remission, and corticosteroid-free remission must be a key therapeutic target.

\subsection{Biologics Induce Remission in the Majority of Patients with UC}

Currently, two biological classes are available for the treatment of UC: TNF antagonists (infliximab, adalimumab, and golimumab) and anti-integrin therapy (vedolizumab) [76]. The development of biologic therapies for the treatment of UC has added an important treatment option, particularly for moderate to severe disease that does not respond to other therapies [2, 76, 77]. Studies of patient preferences have also reported that patients with UC strongly prefer medical therapy to surgical intervention [78, 79]. However, one study reported a low level of use, with $6 \%$ of patients with UC in Western Europe, and 1\% of those in Eastern Europe, receiving infliximab during the first year post-UC diagnosis [80].

However, biologics are not effective in achieving remission in a substantial proportion of patients. Of patients receiving infliximab, approximately $45 \%$ showed a clinical response and $35 \%$ clinical remission after 1 year of treatment [40], remission at 1 year was reported in $32 \%$ of patients responding to adalimumab induction therapy [81], remission was maintained after 1 year of golimumab treatment in approximately $25 \%$ of patients who responded initially [82], and up to $45 \%$ of patients responding to vedolizumab induction treatment were in remission after 1 year [83]. A recent systematic review reported that TNF antagonists reduced the odds of hospitalization by half, and surgery by 33-77\% [84].

In addition to those patients who do not respond to initial biologic treatment, approximately $20-40 \%$ of patients lose response over time [85-87]. The development of antidrug antibodies is known to be a leading contributor to the loss of response to biologic therapies [88], and has been reported in $20 \%$ of patients receiving adalimumab for $\mathrm{CD}$ [89] and up to $60 \%$ of patients with IBD receiving infliximab [90]. A good deal of the secondary loss of response to TNF antagonists could be mitigated by therapeutic drug monitoring to allow dose optimization [91], as well as the use of concomitant immunomodulators, which suppress antidrug antibodies and can re-establish clinical efficacy in some patients [92]. Adverse drug reactions have been shown to be the second most common reason for patient discontinuation of biologic therapies, after primary non-response [93]. Pharmacogenetic studies may identify biomarkers that predict patient response to anti-TNF therapies [94].

Patients with UC could potentially benefit from novel small molecule therapies that do not induce antidrug antibody formation. A number of prospective treatments are also currently under investigation [95-97]. One class of drugs being considered is the Janus kinase inhibitors [98]; clinical efficacy and improvements in HRQoL in moderate to severe UC have been demonstrated with tofacitinib in phase II and III clinical trials [42, 99-102]. In a phase II trial in moderate to severe UC, the sphingosine-1-phosphate receptor agonist 
ozanimod has also been reported to result in a slightly higher rate of clinical remission than placebo [103]. Another pathway as a potential focus for novel therapies includes interleukin (IL)-mediated inflammatory response, targeted by the IL-23 and IL-12 antibody ustekinumab [95]. In addition, the use of fecal microbiota transplantation (FMT) has been suggested as a potential therapeutic strategy for patients with IBD; however, to date, only a small number of studies have investigated the efficacy of FMT in patients with IBD, and results have been inconclusive [104, 105]. Further studies in larger patient cohorts will therefore be required to assess the potential of FMT for IBD.

In summary, biologics fail to induce remission in a substantial proportion of UC patients, and secondary nonresponsiveness develops in up to $40 \%$ of patients who respond initially.

\section{Conclusions}

The development of novel treatments for IBD, including small molecular therapies, continues and should widen the armamentarium of treatment options available to gastroenterologists. In addition to the expanded treatment options, improved surgical decision making and techniques and effective CRC surveillance programs have also contributed to the improvement of prognosis for patients with UC over the past 30 years or so. However, the persistence of a number of misconceptions among a subset of clinicians and healthcare professionals responsible for the management of patients with UC is resulting in suboptimal clinical care for some patients.

Acknowledgements Medical writing support, under the guidance of the authors, was provided by Carole Evans, $\mathrm{PhD}$, on behalf of CMC Connect, a division of McCann Health Medical Communications, Macclesfield, UK, and was funded by Pfizer Inc, New York, NY, USA, in accordance with Good Publication Practice (GPP3) guidelines (Ann Intern Med. 2015;163:461-4).

Author contributions All authors contributed substantially to the conception of this manuscript, drafted the work and revised it critically for important intellectual content, approved the final published version of the manuscript, and are accountable for all aspects of this work.

\section{Compliance with Ethical Standards}

Funding This article was funded by Pfizer Inc, New York, NY, USA. The article processing charge for open access was funded by Pfizer Inc, New York, NY, USA.

Conflict of interest Geert R.A.M. D'Haens has received consulting fees from AbbVie, Ablynx, Amakem, AM Pharma, Avaxia, Biogen, Boehringer Ingelheim, Bristol-Myers Squibb, Celgene, Celltrion, Cosmo, Covidien/Medtronics, Dr. Falk Pharma, Engene, Ferring, Galapagos, Gilead, GlaxoSmithKline, Hospira, Immunic, Johnson and John- son, Lycera, Medimetrics, Millennium/Takeda, Mitsubishi Pharma, MSD, Mundipharma, Novo Nordisk, Pfizer Inc, Prometheus Laboratories/Nestle, Receptos, Robarts Clinical Trials, Salix, Sandoz, Setpoint, Shire, Teva, Tigenix, Tillotts, Topivert, Versant, and Vifor; research grants from AbbVie, Falk, Ferring, MSD, Mundipharma, and Takeda; and lecture and/or speaker bureau fees from AbbVie, Ferring, Johnson and Johnson, Millennium/Takeda, MSD, Mundipharma, Norgine, Pfizer Inc, Shire, Tillotts, and Vifor. James O. Lindsay has received consulting fees from AbbVie, Celgene, Ferring, Janssen, Merck, Pfizer Inc, Robarts Clinical Trials, Shire, and Takeda; research grants from Pfizer Inc/Hospira, MSD, Shire, and Takeda; lecture and/or speaker bureau fees from AbbVie, Allergan, Ferring, Janssen, MSD, Shire, and Takeda; and advisory board fees from AbbVie, Atlantic Healthcare, Ferring, Hospira, Janssen, MSD, NAP, Pfizer Inc, Shire, Takeda, and Vifor. Remo Panaccione has received consulting fees from AbbVie, Amgen, Aptalis, AstraZeneca, Baxter, Biogen, Bristol-Myers Squibb, Celgene, Centocor, Cubist, Eisai, Elan, Ferring, Gilead, GlaxoSmithKline, Janssen, Merck, Pfizer Inc, Robarts Clinical Trials, Salix, Samsung Bioepis, Shire, Takeda, and UCB; research grants from AbbVie, Ferring, Janssen, and Takeda; lecture and/or speaker bureau fees from AbbVie, Aptalis, AstraZeneca, Ferring, Janssen, Merck, Prometheus, Shire, and Takeda; and advisory board fees from Abbott, AbbVie, Amgen, Aptalis, AstraZeneca, Baxter, Bristol-Myers Squibb, Celgene, Centocor, Cubist, Eisai, Elan, Ferring, Genentech, GlaxoSmithKline, Janssen, Merck, Pfizer Inc, Salix, Schering-Plough, Shire, Takeda, and UCB. Stefan Schreiber has received consulting fees from AbbVie, Biogen, Boehringer Ingelheim, Celgene, Celltrion, Ferring, Galapagos, Janssen, MedImmune, MSD, Pfizer Inc/Hospira, Shire, Takeda, and UCB; and lecture and/or speaker bureau fees from AbbVie, Falk, Ferring, MSD, Takeda, and UCB.

Open Access This article is distributed under the terms of the Creative Commons Attribution-NonCommercial 4.0 International License (http://creativecommons.org/licenses/by-nc/4.0/), which permits any noncommercial use, distribution, and reproduction in any medium, provided you give appropriate credit to the original author(s) and the source, provide a link to the Creative Commons license, and indicate if changes were made.

\section{References}

1. Huppertz-Hauss G, Høivik ML, Jelsness-Jørgensen LP, Opheim R, Henriksen M, Høie O, et al. Fatigue in a population-based cohort of patients with inflammatory bowel disease 20 years after diagnosis: The IBSEN study. Scand J Gastroenterol. 2017:52:351-8.

2. Ordás I, Eckmann L, Talamini M, Baumgart DC, Sandborn WJ. Ulcerative colitis. Lancet. 2012;380:1606-19.

3. de Souza HS, Fiocchi C. Immunopathogenesis of IBD: current state of the art. Nat Rev Gastroenterol Hepatol. 2016;13:13-27.

4. Legaki E, Gazouli M. Influence of environmental factors in the development of inflammatory bowel diseases. World J Gastrointest Pharmacol Ther. 2016;7:112-25.

5. Liu TC, Stappenbeck TS. Genetics and pathogenesis of inflammatory bowel disease. Annu Rev Pathol. 2016;11:127-48.

6. Bernklev T, Jahnsen J, Lygren I, Henriksen M, Vatn M, Moum B. Health-related quality of life in patients with inflammatory bowel disease measured with the short form-36: psychometric assessments and a comparison with general population norms. Inflamm Bowel Dis. 2005;11:909-18.

7. Feagan BG, Patel H, Colombel JF, Rubin DT, James A, Mody $\mathrm{R}$, et al. Effects of vedolizumab on health-related quality of life 
in patients with ulcerative colitis: results from the randomised GEMINI 1 trial. Aliment Pharmacol Ther. 2017;45:264-75.

8. Panés J, Louis E, Rutgeerts P. The full picture of ulcerative colitis: the burden, the patient, the treatment. EMJ Gastroenterol. 2015;4:58-65.

9. Molodecky NA, Soon IS, Rabi DM, Ghali WA, Ferris M, Chernoff G, et al. Increasing incidence and prevalence of the inflammatory bowel diseases with time, based on systematic review. Gastroenterology. 2012;142(46-54):e42.

10. Kaplan GG, Ng SC. Understanding and preventing the global increase of inflammatory bowel disease. Gastroenterology. 2017;152:313-21.

11. Feakins RM. Ulcerative colitis or Crohn's disease? Pitfalls and problems. Histopathology. 2014;64:317-35.

12. Satsangi J, Silverberg MS, Vermeire S, Colombel JF. The Montreal classification of inflammatory bowel disease: controversies, consensus, and implications. Gut. 2006;55:749-53.

13. Yantiss RK, Farraye FA, O'Brien MJ, Fruin AB, Stucchi AF, Becker JM, et al. Prognostic significance of superficial fissuring ulceration in patients with severe "indeterminate" colitis. Am J Surg Pathol. 2006;30:165-70.

14. Khor B, Gardet A, Xavier RJ. Genetics and pathogenesis of inflammatory bowel disease. Nature. 2011;474:307-17.

15. Bryant RV, Winer S, Travis SP, Riddell RH. Systematic review: histological remission in inflammatory bowel disease. Is 'complete' remission the new treatment paradigm? An IOIBD initiative. J Crohns Colitis. 2014;8:1582-97.

16. Plevy S, Silverberg MS, Lockton S, Stockfisch T, Croner L, Stachelski J, et al. Combined serological, genetic, and inflammatory markers differentiate non-IBD, Crohn's disease, and ulcerative colitis patients. Inflamm Bowel Dis. 2013;19:1139-48.

17. Ellrichmann M, Wietzke-Braun P, Dhar S, Nikolaus S, Arlt A, Bethge J, et al. Endoscopic ultrasound of the colon for the differentiation of Crohn's disease and ulcerative colitis in comparison with healthy controls. Aliment Pharmacol Ther. 2014;39:823-33.

18. Deepak P, Kolbe AB, Fidler JL, Fletcher JG, Knudsen JM, Bruining DH. Update on magnetic resonance imaging and ultrasound evaluation of Crohn's disease. Gastroenterol Hepatol (N Y). 2016;12:226-36.

19. Bernstein CN, Shanahan F, Anton PA, Weinstein WM. Patchiness of mucosal inflammation in treated ulcerative colitis: a prospective study. Gastrointest Endosc. 1995;42:232-7.

20. Paine ER. Colonoscopic evaluation in ulcerative colitis. Gastroenterol Rep (Oxf). 2014;2:161-8.

21. DeRoche TC, Xiao SY, Liu X. Histological evaluation in ulcerative colitis. Gastroenterol Rep (Oxf). 2014;2:178-92.

22. Sinakos E, Samuel S, Enders F, Loftus EV Jr, Sandborn WJ, Lindor KD. Inflammatory bowel disease in primary sclerosing cholangitis: a robust yet changing relationship. Inflamm Bowel Dis. 2013;19:1004-9.

23. Lecis P, Germanà B, Papa N, Bertiato G, Doglioni C, Galliani E, et al. p-ANCA and ASCA antibodies in the differential diagnosis between ulcerative rectocolitis and Crohn's disease (in Italian). Recent Prog Med. 2002;93:308-13.

24. Bartunková J, Kolárová I, Sedivá A, Hölzelová E. Antineutrophil cytoplasmic antibodies, anti-Saccharomyces cerevisiae antibodies, and specific IgE to food allergens in children with inflammatory bowel diseases. Clin Immunol. 2002;102:162-8.

25. Vasiliauskas EA, Plevy SE, Landers CJ, Binder SW, Ferguson DM, Yang H, et al. Perinuclear antineutrophil cytoplasmic antibodies in patients with Crohn's disease define a clinical subgroup. Gastroenterology. 1996;110:1810-9.

26. Hahnloser D, Pemberton JH, Wolff BG, Larson DR, Crownhart BS, Dozois RR. Results at up to 20 years after ileal pouchanal anastomosis for chronic ulcerative colitis. Br J Surg. 2007;94:333-40.
27. Ikeuchi H, Uchino M, Matsuoka H, Bando T, Matsumoto T, Tomita N, et al. Surgery for ulcerative colitis in 1,000 patients. Int J Colorectal Dis. 2010;25:959-65.

28. Caviglia GP, Dughera F, Ribaldone DG, Rosso C, Abate ML, Pellicano R, et al. Serum zonulin in patients with inflammatory bowel disease: a pilot study. Minerva Med. http://doi org/10.23736/S0026-4806.18.05787-7 (epub 28 Aug 2018).

29. Granlund A, Flatberg A, Østvik AE, Drozdov I, Gustafsson BI, Kidd M, et al. Whole genome gene expression meta-analysis of inflammatory bowel disease colon mucosa demonstrates lack of major differences between Crohn's disease and ulcerative colitis. PLoS One. 2013;8:e56818.

30. Waterman M, Xu W, Stempak JM, Milgrom R, Bernstein CN, Griffiths AM, et al. Distinct and overlapping genetic loci in Crohn's disease and ulcerative colitis: correlations with pathogenesis. Inflamm Bowel Dis. 2011;17:1936-42.

31. Anderson CA, Boucher G, Lees CW, Franke A, D'Amato M, Taylor KD, et al. Meta-analysis identifies 29 additional ulcerative colitis risk loci, increasing the number of confirmed associations to 47. Nat Genet. 2011;43:246-52.

32. Cleynen I, Boucher G, Jostins L, Schumm LP, Zeissig S, Ahmad $\mathrm{T}$, et al. Inherited determinants of Crohn's disease and ulcerative colitis phenotypes: a genetic association study. Lancet. 2016;387:156-67.

33. Conrad K, Roggenbuck D, Laass MW. Diagnosis and classification of ulcerative colitis. Autoimmun Rev. 2014;13:463-6.

34. Truelove SC, Witts LJ. Cortisone in ulcerative colitis; final report on a therapeutic trial. Br Med J. 1955;2:1041-8.

35. Harbord M, Eliakim R, Bettenworth D, Karmiris K, Katsanos K, Kopylov U, et al. Third European evidence-based consensus on diagnosis and management of ulcerative colitis. Part 2: Current management. J Crohns Colitis. 2017;11:769-84.

36. Kornbluth A, Sachar DB, Practice Parameters Committee of the American College of Gastroenterology. Ulcerative colitis practice guidelines in adults: American College of Gastroenterology, Practice Parameters Committee. Am J Gastroenterol. 2010;105:501-23.

37. Mowat C, Cole A, Windsor A, Ahmad T, Arnott I, Driscoll R, et al. Guidelines for the management of inflammatory bowel disease in adults. Gut. 2011;60:571-607.

38. National Institute for Health and Care Excellence. Ulcerative colitis: management. 2016. https://www.nice.org.uk/guidance/ cg166/resources/ulcerative-colitis-management-3510969512 6725. Accessed 25 Jan 2019.

39. Dassopoulos T, Cohen RD, Scherl EJ, Schwartz RM, Kosinski L, Regueiro MD. Ulcerative colitis care pathway. Gastroenterology. 2015;149:238-45.

40. Rutgeerts P, Sandborn WJ, Feagan BG, Reinisch W, Olson A, Johanns J, et al. Infliximab for induction and maintenance therapy for ulcerative colitis. N Engl J Med. 2005;353:2462-76.

41. Taxonera C, Estellés J, Fernández-Blanco I, Merino O, MarínJiménez I, Barreiro-de AM, et al. Adalimumab induction and maintenance therapy for patients with ulcerative colitis previously treated with infliximab. Aliment Pharmacol Ther. 2011;33:340-8.

42. Sandborn WJ, Ghosh S, Panes J, Vranic I, Su C, Rousell S, et al. Tofacitinib, an oral Janus kinase inhibitor, in active ulcerative colitis. N Engl J Med. 2012;367:616-24.

43. Manetti N, Bagnoli S, Rogai F, Bonanomi AG, Vannozzi G, Giannotta M, et al. Disease course and colectomy rate of ulcerative colitis: a follow-up cohort study of a referral center in Tuscany. Inflamm Bowel Dis. 2016;22:1945-53.

44. Sahami S, Konté K, Buskens CJ, Tanis PJ, Löwenberg M, Ponsioen CJ, et al. Risk factors for proximal disease extension and colectomy in left-sided ulcerative colitis. United Eur Gastroenterol J. 2017;5:554-62. 
45. Solberg IC, Lygren I, Jahnsen J, Aadland E, Høie O, Cvancarova $\mathrm{M}$, et al. Clinical course during the first 10 years of ulcerative colitis: results from a population-based inception cohort (IBSEN Study). Scand J Gastroenterol. 2009;44:431-40.

46. Langholz E. Current trends in inflammatory bowel disease: the natural history. Therap Adv Gastroenterol. 2010;3:77-86.

47. Etchevers MJ, Aceituno M, García-Bosch O, Ordás I, Sans M, Ricart E, et al. Risk factors and characteristics of extent progression in ulcerative colitis. Inflamm Bowel Dis. 2009;15:1320-5.

48. Ungaro R, Mehandru S, Allen PB, Peyrin-Biroulet L, Colombel JF. Ulcerative colitis. Lancet. 2017;389:1756-70.

49. Munkholm P. Review article: the incidence and prevalence of colorectal cancer in inflammatory bowel disease. Aliment Pharmacol Ther. 2003;18:1-5.

50. Eaden JA, Abrams KR, Mayberry JF. The risk of colorectal cancer in ulcerative colitis: a meta-analysis. Gut. 2001;48:526-35.

51. Magro F, Gionchetti P, Eliakim R, Ardizzone S, Armuzzi A, Barreiro-de Acosta M, et al. Third European evidence-based consensus on diagnosis and management of ulcerative colitis. Part 1: Definitions, diagnosis, extra-intestinal manifestations, pregnancy, cancer surveillance, surgery, and ileo-anal pouch disorders. J Crohns Colitis. 2017;11:649-70.

52. Rutter MD, Saunders BP, Wilkinson KH, Rumbles S, Schofield G, Kamm MA, et al. Thirty-year analysis of a colonoscopic surveillance program for neoplasia in ulcerative colitis. Gastroenterology. 2006;130:1030-8.

53. Castaño-Milla C, Chaparro M, Gisbert JP. Systematic review with meta-analysis: the declining risk of colorectal cancer in ulcerative colitis. Aliment Pharmacol Ther. 2014;39:645-59.

54. Rutegård $\mathrm{M}$, Palmqvist R, Stenling R, Lindberg J, Rutegård $\mathrm{J}$. Efficiency of colorectal cancer surveillance in patients with ulcerative colitis: 38 years' experience in a patient cohort from a defined population area. Scand J Surg. 2017;106:133-8.

55. Choi CH, Rutter MD, Askari A, Lee GH, Warusavitarne J, Moorghen M, et al. Forty-year analysis of colonoscopic surveillance program for neoplasia in ulcerative colitis: an updated overview. Am J Gastroenterol. 2015;110:1022-34.

56. Arora Z, Shen B. Biological therapy for ulcerative colitis. Gastroenterol Rep (Oxf). 2015;3:103-9.

57. Binder V, Hendriksen C, Kreiner S. Prognosis in Crohn's diseasebased on results from a regional patient group from the county of Copenhagen. Gut. 1985;26:146-50.

58. Greenstein AJ, Sachar DB, Smith H, Janowitz HD, Aufses AH Jr. A comparison of cancer risk in Crohn's disease and ulcerative colitis. Cancer. 1981;48:2742-5.

59. Burisch J, Munkholm P. Inflammatory bowel disease epidemiology. Curr Opin Gastroenterol. 2013;29:357-62.

60. Lutgens MW, van Oijen MG, van der Heijden GJ, Vleggaar FP, Siersema PD, Oldenburg B. Declining risk of colorectal cancer in inflammatory bowel disease: an updated meta-analysis of population-based cohort studies. Inflamm Bowel Dis. 2013;19:789-99.

61. Laine L, Kaltenbach T, Barkun A, McQuaid KR, Subramanian V, Soetikno R. SCENIC international consensus statement on surveillance and management of dysplasia in inflammatory bowel disease. Gastroenterology. 2015;148:639-51.

62. National Institute for Health and Care Excellence. Colorectal cancer prevention: colonoscopic surveillance in adults with ulcerative colitis, Crohn's disease or adenomas. 2011. https:// www.nice.org.uk/guidance/cg118. Accessed 25 Jan 2019.

63. Leong RW, Ooi M, Corte C, Yau Y, Kermeen M, Katelaris PH, et al. Full-spectrum endoscopy improves surveillance for dysplasia in patients with inflammatory bowel diseases. Gastroenterology. 2017;152(1337-44):e3.

64. Iannone A, Ruospo M, Wong G, Principi M, Barone M, Strippoli GF, et al. Chromoendoscopy for surveillance in ulcerative colitis and Crohn's disease: a systematic review of randomized trials. Clin Gastroenterol Hepatol. 2017;15:1684-97.

65. Gomollón F, Dignass A, Annese V, Tilg H, Van Assche G, Lindsay JO, et al. 3rd European evidence-based consensus on the diagnosis and management of Crohn's disease 2016: Part 1: Diagnosis and medical management. J Crohns Colitis. 2017;11:3-25.

66. Khan HMW, Mehmood F, Khan N. Optimal management of steroid-dependent ulcerative colitis. Clin Exp Gastroenterol. 2015;8:293-302.

67. Ardizzone S, Maconi G, Russo A, Imbesi V, Colombo E, Bianchi Porro G. Randomised controlled trial of azathioprine and 5-aminosalicylic acid for treatment of steroid dependent ulcerative colitis. Gut. 2006;55:47-53.

68. Fraser AG, Orchard TR, Jewell DP. The efficacy of azathioprine for the treatment of inflammatory bowel disease: a 30 year review. Gut. 2002;50:485-9.

69. Maté-Jiménez J, Hermida C, Cantero-Perona J, Moreno-Otero R. 6-Mercaptopurine or methotrexate added to prednisone induces and maintains remission in steroid-dependent inflammatory bowel disease. Eur J Gastroenterol Hepatol. 2000;12:1227-33.

70. Campieri M. New steroids and new salicylates in inflammatory bowel disease: a critical appraisal. Gut. 2002;50:III43-6.

71. Llaó J, Naves JE, Ruiz-Cerulla A, Gordillo J, Mañosa M, Maisterra S, et al. Improved outcome of acute severe ulcerative colitis while using early predictors of corticosteroid failure and rescue therapies. Dig Liver Dis. 2016;48:608-12.

72. Rubin DT, Mody R, Davis KL, Wang CC. Real-world assessment of therapy changes, suboptimal treatment and associated costs in patients with ulcerative colitis or Crohn's disease. Aliment Pharmacol Ther. 2014;39:1143-55.

73. Loftus EV Jr, Achenbach SJ, Sandborn WJ, Tremaine WJ, Oberg AL, Melton LJ 3rd. Risk of fracture in ulcerative colitis: a population-based study from Olmsted County, Minnesota. Clin Gastroenterol Hepatol. 2003;1:465-73.

74. Selinger CP, Parkes GC, Bassi A, Fogden E, Hayee B, Limdi JK, et al. A multi-centre audit of excess steroid use in 1176 patients with inflammatory bowel disease. Aliment Pharmacol Ther. 2017;46:964-73.

75. Lasch K, Liu S, Ursos L, Mody R, King-Concialdi K, DiBonaventura $\mathrm{M}$, et al. Gastroenterologists' perceptions regarding ulcerative colitis and its management: results from a large-scale survey. Adv Ther. 2016;33:1715-27.

76. Sofia MA, Rubin DT. Current approaches for optimizing the benefit of biologic therapy in ulcerative colitis. Ther Adv Gastroenterol. 2016;9:548-59.

77. O'Toole A, Moss AC. Optimizing biologic agents in ulcerative colitis and Crohn's disease. Curr Gastroenterol Rep. 2015;17:32.

78. Bewtra M, Kilambi V, Fairchild AO, Siegel CA, Lewis JD, Johnson FR. Patient preferences for surgical versus medical therapy for ulcerative colitis. Inflamm Bowel Dis. 2014;20:103-14.

79. Byrne CM, Tan KK, Young JM, Selby W, Solomon MJ. Patient and clinician preferences for surgical and medical treatment options in ulcerative colitis. Colorectal Dis. 2014;16:285-92.

80. Burisch J, Pedersen N, Cukovic-Cavka S, Turk N, Kaimakliotis I, Duricova D, et al. Initial disease course and treatment in an inflammatory bowel disease inception cohort in Europe: the ECCO-EpiCom cohort. Inflamm Bowel Dis. 2014;20:36-46.

81. Colombel JF, Sandborn WJ, Ghosh S, Wolf DC, Panaccione R, Feagan B, et al. Four-year maintenance treatment with adalimumab in patients with moderately to severely active ulcerative colitis: data from ULTRA 1, 2, and 3. Am J Gastroenterol. 2014;109:1771-80.

82. Sandborn WJ, Feagan BG, Marano C, Zhang H, Strauss R, Johanns J, et al. Subcutaneous golimumab maintains clinical 
response in patients with moderate-to-severe ulcerative colitis. Gastroenterology. 2014;146(96-109):e1.

83. Feagan BG, Rutgeerts P, Sands BE, Hanauer S, Colombel JF, Sandborn WJ, et al. Vedolizumab as induction and maintenance therapy for ulcerative colitis. N Engl J Med. 2013;369:699-710.

84. Mao EJ, Hazlewood GS, Kaplan GG, Peyrin-Biroulet L, Ananthakrishnan AN. Systematic review with meta-analysis: comparative efficacy of immunosuppressants and biologics for reducing hospitalisation and surgery in Crohn's disease and ulcerative colitis. Aliment Pharmacol Ther. 2017;45:3-13.

85. Billioud V, Sandborn WJ, Peyrin-Biroulet L. Loss of response and need for adalimumab dose intensification in Crohn's disease: a systematic review. Am J Gastroenterol. 2011;106:674-84.

86. Gisbert JP, Panés J. Loss of response and requirement of infliximab dose intensification in Crohn's disease: a review. Am J Gastroenterol. 2009;104:760-7.

87. Roblin X, Marotte H, Leclerc M, Del Tedesco E, Phelip JM, Peyrin-Biroulet L, et al. Combination of C-reactive protein, infliximab trough levels, and stable but not transient antibodies to infliximab are associated with loss of response to infliximab in inflammatory bowel disease. J Crohns Colitis. 2015;9:525-31.

88. Vincent FB, Morand EF, Murphy K, Mackay F, Mariette X, Marcelli C. Antidrug antibodies (ADAb) to tumour necrosis factor (TNF)-specific neutralising agents in chronic inflammatory diseases: a real issue, a clinical perspective. Ann Rheum Dis. 2013;72:165-78.

89. Baert F, Kondragunta V, Lockton S, Vande Casteele N, Hauenstein S, Singh S, et al. Antibodies to adalimumab are associated with future inflammation in Crohn's patients receiving maintenance adalimumab therapy: a post hoc analysis of the Karmiris trial. Gut. 2016;65:1126-31.

90. Nanda KS, Cheifetz AS, Moss AC. Impact of antibodies to infliximab on clinical outcomes and serum infliximab levels in patients with inflammatory bowel disease (IBD): a meta-analysis. Am J Gastroenterol. 2013;108:40-7.

91. Cheifetz A. Overview of therapeutic drug monitoring of biologic agents in patients with inflammatory bowel disease. Gastroenterol Hepatol (N Y). 2017;13:556-9.

92. Strik AS, van den Brink GR, Ponsioen C, Mathot R, Löwenberg M, D'Haens GR. Suppression of anti-drug antibodies to infliximab or adalimumab with the addition of an immunomodulator in patients with inflammatory bowel disease. Aliment Pharmacol Ther. 2017;45:1128-34.
93. Feagins LA, Waljee A, Hou JK, Gu P, Kanjo S, Rudrapatna V, et al. Incidence of and predictors for early discontinuation of biological therapies in veteran patients with inflammatory bowel disease. Inflamm Bowel Dis. 2017;23:1434-9.

94. Bek S, Nielsen JV, Bojesen AB, Franke A, Bank S, Vogel U, et al. Systematic review: genetic biomarkers associated with anti-TNF treatment response in inflammatory bowel diseases. Aliment Pharmacol Ther. 2016;44:554-67.

95. Ungar B, Kopylov U. Advances in the development of new biologics in inflammatory bowel disease. Ann Gastroenterol. 2016;29:243-8.

96. Chan $\mathrm{HC}, \mathrm{Ng} \mathrm{SC}$. Emerging biologics in inflammatory bowel disease. J Gastroenterol. 2017;52:141-50.

97. Naganuma M, Mizuno S, Nanki K, Sugimoto S, Kanai T. Recent trends and future directions for the medical treatment of ulcerative colitis. Clin J Gastroenterol. 2016;9:329-36.

98. Olivera P, Danese S, Peyrin-Biroulet L. JAK inhibition in inflammatory bowel disease. Expert Rev Clin Immunol. 2017;13:693-703.

99. Panés J, Su C, Bushmakin AG, Cappelleri JC, Mamolo C, Healey $\mathrm{P}$. Randomized trial of tofacitinib in active ulcerative colitis: analysis of efficacy based on patient-reported outcomes. BMC Gastroenterol. 2015;15:14.

100. Sandborn WJ, Su C, Sands BE, D'Haens GR, Vermeire S, Schreiber S, et al. Tofacitinib as induction and maintenance therapy for ulcerative colitis. N Engl J Med. 2017;376:1723-36.

101. Danese S, D’Amico F, Bonovas S, Peyrin-Biroulet L. Positioning tofacitinib in the treatment algorithm of moderate to severe ulcerative colitis. Inflamm Bowel Dis. 2018;24:2106-12.

102. Hanauer S, Panaccione R, Danese S, Cheifetz A, Reinisch W, Higgins PDR, et al. Tofacitinib induction therapy reduces symptoms within 3 days for patients with ulcerative colitis. Clin Gastroenterol Hepatol. 2019;17:139-47.

103. Sandborn WJ, Feagan BG, Wolf DC, D'Haens G, Vermeire S, Hanauer SB, et al. Ozanimod induction and maintenance treatment for ulcerative colitis. N Engl J Med. 2016;374:1754-62.

104. Imdad A, Nicholson MR, Tanner-Smith EE, Zackular JP, GomezDuarte OG, Beaulieu DB, et al. Fecal transplantation for treatment of inflammatory bowel disease. Cochrane Database Syst Rev. 2018;11:CD012774.

105. Moayyedi P. Fecal transplantation: any real hope for inflammatory bowel disease? Curr Opin Gastroenterol. 2016;32:282-6. 